\title{
Effect of Boride Incubation Time During the Formation of $\mathrm{Fe}_{2} \mathrm{~B}$ Phase
}

\author{
Bendaoud Mebarek ${ }^{a}$, Abdelbasset Benguelloula ${ }^{b}$, Abdelouahab Zanoun $^{c}$ \\ a Ibn Khaldoun University of Tiaret, BP 78 Zaaroura, Tiaret 14000, Algeria \\ ${ }^{b}$ University of Science and Technology of Oran, BP 1523 El M'Naouer, Algéria \\ ${ }^{c}$ National Polytechnic School Maurice Audin (ENPO-MA) of Oran, Algeria
}

Received: July 13, 2017; Revised: October 17, 2017; Accepted: October 18, 2017

\begin{abstract}
Our present study focuses on the numerical simulation of the boronized layer growth kinetics on the iron substrate of the XC38 steel, the boronizing treatment is performed in a liquid medium composed of borax and silicon carbide. We mainly calculated the incubation time of the boronized layer formation. Aimed at estimating the boronizing treatment kinetics of XC38 steel, we initially used experimental data. The study was conducted to determine the law of borided layers growth and estimate the boron diffusion coefficient in the $\mathrm{Fe}_{2} \mathrm{~B}$ layer. The diffusion coefficient obtained from this experiment is:

$$
D_{\mathrm{Fe}_{2} \mathrm{~B}}=1.388 \times 10^{-4} \exp \left(-\frac{207.8 \times 10^{3} j}{R T}\right)\left(\mathrm{m}^{2} \mathrm{~s}^{-1}\right)
$$

In order to calculate the incubation time of the $\mathrm{Fe}_{2} \mathrm{~B}$ layer, we adapted the mathematical model, which is based on the second law of Fick. This model takes into account the thermodynamic properties of the Fe-B phase diagram. The comparison of the results obtained by the simulation with those obtained experimentally verifies the validity of the theoretical study and a good agreement was obtained as well.
\end{abstract}

Keywords: Boronizing, Incubation time, $\mathrm{Fe}_{2} \mathrm{~B}$, Numerical simulation, Coefficient.

\section{Introduction}

Surface treatments are often a technical-economic solution to solve materials problems ${ }^{1}$. Different processes are applied to treat the metals surfaces. They are related to the chemical composition and mechanical properties of the metal ${ }^{1,2}$.

Boronizing steels is a thermochemical treatment to improve the hardness ( $>1600 \mathrm{HV})$, the resistance to adhesive and abrasive wear and resistance to attack by acids and molten metals ${ }^{3}$. Boronizing is a boron diffusion process in steel or other metals, generally performed between $850^{\circ} \mathrm{C}$ and $1050^{\circ} \mathrm{C}^{4,5}$.

There are three kinds of sources that provide the boron integrated in the substratum, solid (powder or paste), liquid (with or without electrolysis) and gaseous boron-rich atmospheres $^{1-6}$. In a liquid or solid medium, borided layers are easily formed on the metal ${ }^{2}$. In industrial applications the gaseous boronizing method requires complex equipment ${ }^{1}$.

Usually, boronizing leads to the formation of two kinds of iron bodies $\mathrm{FeB}$ and/or $\mathrm{Fe}_{2} \mathrm{~B}$, according to the $\mathrm{Fe}-\mathrm{B}$ phase diagram $^{7,8}$. The FeB has an orthorhombic structure and its boron content is 16 wt.\%. The $\mathrm{Fe}_{2} \mathrm{~B}$ has a tetragonal crystal structure and its boron content is 8.83 wt. $\%{ }^{9}$.

In this study, we prefer $\mathrm{Fe}_{2} \mathrm{~B}$ over $\mathrm{FeB}$, which is less harder and more tougher than $\mathrm{FeB}$ iron boride, due to its thermal expansion coefficient, which is lower than; that of steel and allows development of compressive stresses on the substrate surface ${ }^{1-10}$.

*e-mail: mebarekbendaoud@yahoo.fr
The structure of $\mathrm{Fe}_{2} \mathrm{~B}$ layer is saw-toothed and this is typical in iron and low-carbon steels, from the fact that the diffusion coefficient in the $\mathrm{Fe}_{2} \mathrm{~B}$ is highly anisotropic; the diffusion is promoted in the grain direction [300]. The thickness and the quality of boronized layer during a boronizing treatment depend on the chemical composition of the medium in contact with the surface, as well as temperature and duration of treatment ${ }^{11}$.

On the theoretical level, there are several studies have been undertaken to study boronizing and several mathematical models have been developed ${ }^{12,13}$.

For instance the growth kinetics of borided layers were studied by empirical models based on Fick's laws ${ }^{14}$. This allowed the characterization of $\mathrm{FeB}$ and $\mathrm{Fe}_{2} \mathrm{~B}$ phases, and the diffusivity of boron parameters.

In this paper, we numerically study the thermochemical boronizing of the XC38 steel dipped into a salt bath (70\% borax $30 \%$ of silicon carbide) at temperatures between $850^{\circ}$ $\mathrm{C}$ to $1050^{\circ} \mathrm{C}$ for 2,4 and 6 hours $^{15}$.

We proceed to calculate the diffusion coefficient from experimental data; this coefficient is used in the mathematical model to estimate the kinetics of boronizing the XC38 steel. We remind that the diffusion coefficient (D) of boron in the steel is a characteristic of a mobility to a defined temperature. This phenomenon associated with the atoms agitation will change with temperature in the same direction as the defect concentration and the entropy of the system. 
We noticed that a very limited number of papers were cited about the effects of the incubation time on the formation of the boride layer. Thus, to calculate the incubation time of the $\mathrm{Fe}_{2} \mathrm{~B}$ borided layer, we used the mathematical model developed in reference ${ }^{16}$, the model is based on Fick's laws and it does not take into consideration the incubation time of the boronized layer. In the present work, we improved the mathematical model considering the incubation time of the boronized layer as a parameter for calculating the thickness of the boronized layer.

\section{Estimation of boron activation energy}

The diffusion coefficient can be related with the processing time and the thickness of the boronized layer by Arrhenius expression ${ }^{17,18}$. To estimate the boron activation energy, we must have a minimum of three treatment temperatures and thicknesses' values of the layer for each temperature. From the experimental data ${ }^{15}$, we can estimate the activation energy of the diffusion of boron in the XC38 steel substrate using the equation (1):

$$
u^{2}=D_{0} t \exp \left(-\frac{Q}{R T}\right)
$$

The variable $u$ represents the layer thickness $(\mu \mathrm{m}), \mathrm{D}_{0}$ is the diffusion coefficient of boron $\left(\mu \mathrm{m}^{2} / \mathrm{s}\right), \mathrm{t}$ is the time (s) of boronizing, $\mathrm{Q}$ is the value of the activation energy measured in Joule/mole, $\mathrm{R}$ is the gas constant $(\mathrm{R}=8.314$ Joule/mole.K $)$ and $\mathrm{T}$ is the temperature in Kelvin.

Figure 1 depicts the evolution of the thickness of the boronized layer $\left(\mathrm{Fe}_{2} \mathrm{~B}\right)$ of the steel according to the reciprocal temperature.

Using a linear regression (taking the natural logarithm of both sides of equation (1)), we can also deduce the activation energy of boron which is estimated at a value of $207.8 \mathrm{~kJ} /$ mol. This activation energy is interpreted as the boron

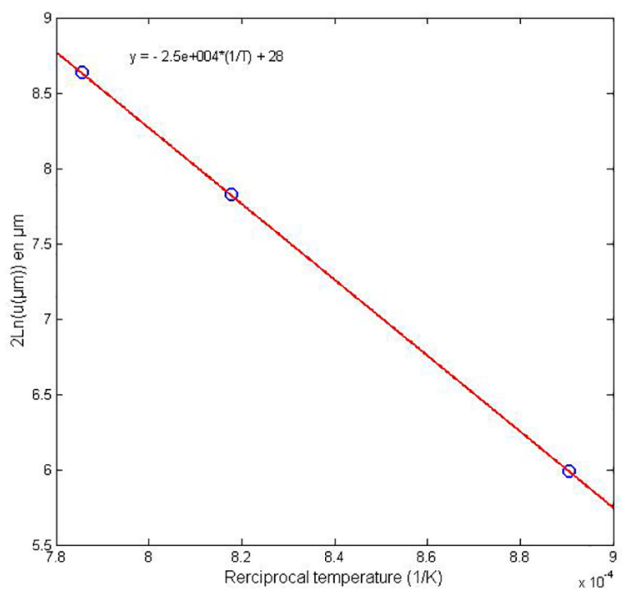

Figure 1. Reciprocal temperature dependence of the boride layer thickness formed on XC38 steels after $2 \mathrm{~h}$. diffusion through the direction $\left[\begin{array}{lll}0 & 0 & 1\end{array}\right]$ in the $\mathrm{Fe}_{2} \mathrm{~B}$ phase. Table 1 shows the $\mathrm{Q}$ values reported by other researchers.

Table 1 compares the boron activation energies determined on the XC38 steel according to different methods of boronizing process. It is concluded that the estimated energy of activation in the case of XC38 steel can be compared to the values found in literature ${ }^{19}$. The values of these activation energies depend on the chemical composition of the substrate and the boronizing process used.

Diffusion coefficients are very important parameters for the simulation, in both applications and calculations, it is always necessary to examine carefully if the nature of the coefficient of diffusion, or its numerical value selected responds well to the studied problem.

The diffusion coefficient values found in the literature show large variations, this leads to changes in the estimation of boron growth kinetics.

Assuming the Arrhenius relation for the diffusion process, a diffusivity of boron in $\mathrm{Fe}_{2} \mathrm{~B}$ was obtained:

$$
D_{F_{C Q B}}=1.388 \times 10^{-4} \exp \left(-\frac{207.8 \times 10^{3} j}{R T}\right)\left(m^{2} s^{-1}\right)
$$

\section{Mathematical model to calculate the incubation time of the $\mathrm{Fe}_{2} \mathrm{~B}$ phase}

\subsection{The diffusion model}

To calculate the incubation time of the boronized layer, we used the mathematical model ${ }^{16}$. This model is based on the solution of Fick's diffusion equation in a semi-infinite medium and on the assumption that the boronizing thermochemical treatment is a balancing process.

In this model the boronized layer $\mathrm{Fe}_{2} \mathrm{~B}$ is formed instantly at $\mathrm{t}=0$ and immediately covers the surface (the incubation time is negligible $\tau=0$ ). The model allows the estimation of the growth rate interface $\left(\mathrm{Fe}_{2} \mathrm{~B} / \gamma-\mathrm{Fe}\right)$.

The mathematical diffusion model is based on the phenomenological equations of Fick. The boron concentration profile is described by the solution of the diffusion equation given by Fick (2):

$$
\frac{\partial C_{i}(x, t)}{\partial t}=D_{i} \frac{\partial^{2} C_{i}(x, t)}{\partial x^{2}}
$$

Table 1. Comparison between the obtained values of activation energies of the boron.

\begin{tabular}{ccc}
\hline $\begin{array}{c}\text { Activation Energy } \\
\text { Q (kJ/mole })\end{array}$ & Boronizing method/steel & Reference \\
\hline 157 & Solid powder/XC38 & Keddam et al. ${ }^{19}$ \\
198 & Solid powder/AISI 316 & Campos et al. ${ }^{24}$ \\
174.6 & Liquid/AISI 316L & Mebarek et al. ${ }^{26}$ \\
239.4 & paste boriding/AISIM2 & Campos et al. ${ }^{27}$ \\
215 & Salt boriding/AISI 4140 & Sen et al. ${ }^{25}$ \\
207.8 & Liquid/XC38 & Present work \\
\hline
\end{tabular}


$\mathrm{C}_{\mathrm{i}}(\mathrm{x}, \mathrm{t})$ represents the boron concentration at the depth $\mathrm{x}, \mathrm{t}$ is the duration of the diffusion at temperature. $\mathrm{T}$ is the diffusion coefficient in $\mathrm{m}^{2} \mathrm{~s}^{-1}$, $\mathrm{i}$ represents the phase $(\mathrm{i}=$ $\mathrm{FeB}, \mathrm{Fe}_{2} \mathrm{~B}$ or $\left.\mathrm{Fe}\right)$.

Figure 2 illustrates the boron concentration distribution along the depth of the control surface for a given temperature and under a boron potential which allows the formation of a single-phase $\mathrm{Fe}_{2} \mathrm{~B}$ layer on the substrate.

The general solution of equation (2) for each phase $i$, is given by equation (3):

$$
C_{i}(x, t)=A_{i}+B_{i} \operatorname{erf}\left(\frac{x}{2 \sqrt{D_{i} t}}\right)
$$

erf is the Gaussian error function, $\mathrm{A}_{\mathrm{i}}$ and $\mathrm{B}_{\mathrm{i}}$ are constants dependent on the initial conditions and limits. $i=\left(\mathrm{Fe}_{2} \mathrm{~B}, \gamma-\mathrm{Fe}\right)$.

In our diffusion model, it is considered that:

- The flow of boron atoms is perpendicular to the sample surface and the interface $\left(\mathrm{Fe}_{2} \mathrm{~B} / \gamma-\mathrm{Fe}\right)$ runs parallel to the sample surface.

- The growth of the position of the interface according to time is parabolic.

- The boronized layer is thin compared to the thickness of the sample.

- The porosity effect does not exist in the surface of the material.

- The boron diffusion coefficients in different phases do not change in respect to the boron concentration.

- The boronized layer $\mathrm{Fe}_{2} \mathrm{~B}$ is formed instantly at $\mathrm{t}=0$ and immediately covers the surface (the incubation time is negligible $\tau=0$ ).

Equation (2) subject to the following boundary conditions:

- At initial condition and limits:

$C(x>0, t=0)=0, C(0=0, t>0)=C_{B}^{S / F e_{2} B}$,

$C(x=\infty, t)=0$

- At the interface:

$C_{\mathrm{Fe}_{2} B}\left(\lambda_{\text {sim }}, t\right)=C_{B}^{F e_{2} B / \gamma-F e}, C_{\gamma-F e}\left(\lambda_{s i m}, t\right)=C_{B}^{\gamma-F e / F e_{2} B}$

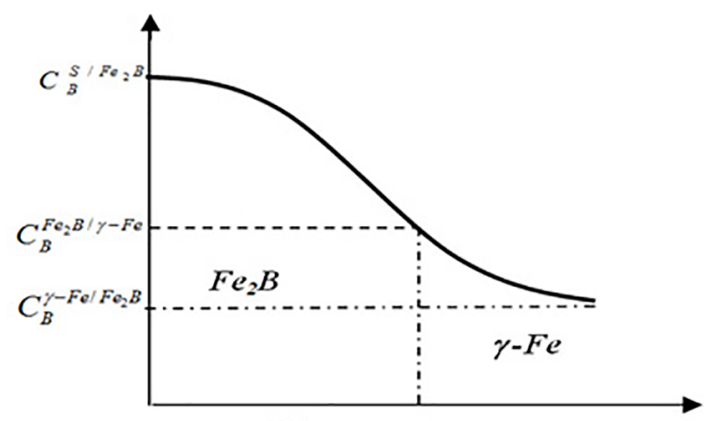

Distance $\lambda$

Figure 2. Diagram of boron concentration profile (Fe2B layer). Fig.2. Diagram of boron concentration profile ( $\mathrm{Fe} 2 \mathrm{~B}$ layer).
$C_{B}^{S / F e e_{2} B}$ : the boron concentration at the sample surface.

$C_{B}^{F e_{2} / \gamma-F e}, C_{B}^{\gamma-F_{e} / F_{2} B}$ : boron concentrations in the $\mathrm{Fe}_{2} \mathrm{~B}$ interface/austenite.

From equation (2) and (3), the boron concentrations in each phase are as follows:

$$
\begin{gathered}
C_{F_{e, B} B}(x, t)=C_{B}^{S S F_{e Q B} B}+\frac{C_{B}^{F_{e} B / \gamma-F_{e}}-C_{B}^{S / F_{e} B}}{\operatorname{erf}\left(\frac{k}{2 \sqrt{D_{1}}}\right)} \times \operatorname{erf}\left(\frac{x}{2 \sqrt{D_{1} t}}\right) \\
C_{\gamma-F e}(x, t)=\frac{C_{B}^{\gamma-F e / F e B}}{\operatorname{erfc}\left(\frac{k}{2 \sqrt{D_{2}}}\right)} \times \operatorname{erfc}\left(\frac{x}{2 \sqrt{D_{2} t}}\right)
\end{gathered}
$$

$\operatorname{erfc}$ is the complementary error function $\operatorname{erfc}(x)=1-\operatorname{erf}(x)$.

The mass balance equation for the $\mathrm{Fe}_{2} \mathrm{~B} / \gamma$-Fe interface is obtained from the following equation:

$$
\begin{gathered}
\left(\frac{1}{2}\left(C_{B}^{S / F_{e 2 B}}-C_{B}^{F_{e} B / \gamma-F_{e}}\right)+\left(C_{B}^{F_{e} B / \gamma-F_{e}}-C_{B}^{\gamma-F_{e} / F_{2} B}\right)\right) \cdot \frac{d \lambda_{\text {sim }}}{d t}= \\
\left(j_{F_{2} B}-j_{\gamma-F_{e}}\right)_{x=\lambda_{\text {im }}} \\
\lambda_{\text {sim }}=k \sqrt{t}
\end{gathered}
$$

Where $\mathrm{k}$ is the growth rate constant, $\lambda_{\text {sim }}$ is the simulated thickness of the boronized layer $\mathrm{Fe}_{2} \mathrm{~B}$ and $\mathrm{t}$ the boronizing time.

After simplifying equation (6), we find:

$$
\begin{aligned}
& f(k)=p_{0} \times k+\left(\frac{2}{\sqrt{\pi}}\right) \times \\
& {\left[\frac{p_{1}}{\operatorname{erf}\left(\frac{k}{2 \sqrt{D_{F e 2 B}}}\right)} e^{-\frac{k^{2}}{4 D_{F_{e} B}}}+\frac{p_{2}}{\operatorname{erfc}\left(\frac{k}{2 \sqrt{D_{\gamma-F e}}}\right)} e^{-\frac{k^{2}}{4 D_{\gamma-F e}}}\right]=0}
\end{aligned}
$$

Where:

$$
\begin{aligned}
p_{0} & =\frac{\left(C_{B}^{S / F e_{2} B}-C_{B}^{F e_{2} B / \gamma-F e}\right)+2\left(C_{B}^{F e_{2} B / \gamma-F e}-C_{B}^{\gamma-F e / F e_{2} B}\right)}{4} \\
p_{1} & =\frac{D_{F e_{2} B}\left(C_{B}^{S / F e_{2} B}-C_{B}^{F e_{2} B / \gamma-F e}\right)}{2 \sqrt{D_{F e_{2} B}}} \\
p_{2} & =\frac{D_{\gamma-F e}\left(C_{B}^{F e_{2} B / \gamma-F e}-C_{B}^{\gamma-F e / F e_{2} B}\right)}{2 \sqrt{D_{F e_{2} B}}}
\end{aligned}
$$

To find a positive value of the growth rate constant $(\mathrm{k})$, the solution of the non-linear Equation (8), $f(k)=0$ is carried out using a numerical method. This function is non-linear; it can be solved by the Newton-Raphson's numerical method.

The important parameters for the simulation are temperature, processing time, boron diffusivity in each phase and its concentration. For the $\mathrm{Fe}_{2} \mathrm{~B}$ phase, we used the previously determined diffusion coefficient.

For the $\gamma$-Fe phase, we used the diffusion coefficient found in $\mathrm{Ref}^{16}$. The boron concentrations in the interfaces $\mathrm{Fe}_{2} \mathrm{~B} / \gamma-\mathrm{Fe}$ and $\gamma-\mathrm{Fe} / \mathrm{Fe}_{2} \mathrm{~B}$ were taken from $\operatorname{Refs}^{5-20}$ :

$C_{B}^{\mathrm{Fe}_{2} \mathrm{~B} / \gamma-\mathrm{Fe}}=8,83 w t . \%, C_{B}^{\gamma-\mathrm{Fe} / \mathrm{Fe}_{2} \mathrm{~B}}=35 \times 10^{-4} w t . \%$

\subsection{Incubation time calculation}

For the formation of the boronized layers Casdesus et al. ${ }^{21}$ proposed a description of the transformations taking place in the steel following the progressive diffusion of boron in 
the substrate, according to this mechanism, the boron atoms released by the boronizing medium are adsorbed on the substrate surface then go into solution in the steel.

After some boron saturation and after a certain incubation time $\tau$, which depends on the temperature of treatment ${ }^{22}$, the first germs of $\mathrm{Fe}_{2} \mathrm{~B}$ appear on the most reactive points of the substrate surface (scratches, seals grains, dislocations ...) the incubation time corresponds to the onset of crystal $\mathrm{Fe}_{2} \mathrm{~B}$ boride on the substrate surface.

After a certain time of incubation $\tau \neq 0$ as shown in ${ }^{23,24}$, the crystals of the $\mathrm{Fe}_{2} \mathrm{~B}$ phase form as needles, growing in the crystallographic direction [ $\left[\begin{array}{lll}0 & 0 & 2\end{array}\right]$, parallel to the boron diffusion flow.

To calculate the incubation time, the mathematical model ${ }^{16}$ and experimental data ${ }^{15}$ have been used; the difference between data obtained experimentally and by simulation allowed us to determine the incubation time, it is expressed by the following equation:

$$
\lambda_{\mathrm{I}}(\mathrm{t}, \mathrm{T})=\left(\lambda_{\text {sim }}-\lambda_{\text {exp }}\right)=\left(k \sqrt{t}-\lambda_{\text {exp }}\right)
$$

and

$$
\lambda_{\mathrm{I}}(\mathrm{t}, \mathrm{T})=k \sqrt{\tau}
$$

Where $\mathrm{k}$ is the growth rate constant, the variable $\lambda_{\mathrm{I}}$ represents the thickness corresponds to the incubation time $(\mu \mathrm{m}), \lambda_{\text {sim }}$ is the simulated thickness with $\tau=0$ and the $\lambda_{\text {exp }}$ thickness is experimentally obtained.

$\tau$ : the incubation time of $\mathrm{Fe}_{2} \mathrm{~B}$ formation.

$\mathrm{t}$ : the boronizing time.

$\mathrm{T}$ : the temperature of treatment.

From the two equations (9) and (10), we have the expression of incubation time:

$$
\tau(t, T)=\frac{\left(k \sqrt{t}-\lambda_{\text {exp }}\right)^{2}}{k}=\frac{\left(f^{-1}(0) \sqrt{t}-\lambda_{\text {exp }}\right)^{2}}{f^{-1}(0)}
$$

\section{Experimental Procedure}

In order to test the validity of the present model, we used the results obtained from boronizing experiments on
XC38 steel taken from our own experimental data published recently ${ }^{15}$.

Samples of XC38 steel were selected for boronizing, whose nominal composition was $\mathrm{C} \approx 0.38, \mathrm{Cr}<0.1, \mathrm{Cu}<0.05$, $\mathrm{Ni} \approx 0.045, \mathrm{Co} \approx 0.17, \mathrm{Si} \approx 0.34, \mathrm{Mn} \approx 0.67$ wt. $\%$ and balance $\mathrm{Fe}$ ).

The electrochemical boronizing experiments were carried out in a liquid medium composed of $70 \%$ borax and $30 \%$ silicon carbide $\left(70 \%\right.$ of $\mathrm{Na}_{2} \mathrm{~B}_{4} \mathrm{O}_{7}$ and $30 \%$ of $\left.\mathrm{SiC}\right)$. The treatment was done at three different temperatures $850^{\circ} \mathrm{C}$, $950{ }^{\circ} \mathrm{C}$ and $1000{ }^{\circ} \mathrm{C}$ with three treatment times 2,4 and $6 \mathrm{~h}$.

The formation of the $\mathrm{Fe}_{2} \mathrm{~B}$ boride was confirmed by optical microscope observations.

\section{Results and Discussion}

We used the previous mathematical model ${ }^{16}$, which does not consider the incubation time. For a boron concentration at the surface of $8.91 \mathrm{wt} . \%$, We get the values of the constants of the simulated growth rate for different temperatures (Table 2).

From Table 2, we note that the variation of the growth rate constant increases if the temperature of treatment increases as well and the diffusion process is very fast.

From the growth rate constant previously determined, we calculate the thickness of the boronized layer $\left(\lambda_{\text {sim }}\right)$.

This simulation model can predict the boron depthconcentration profiles for each phase.

Table 3 shows the simulated values of the incubation time of the $\mathrm{Fe}_{2} \mathrm{~B}$ phase as a function of time ( $\mathrm{t}$ ) and processing temperature $(\mathrm{T})$ (equation 11); note that the incubation time of $\mathrm{Fe}_{2} \mathrm{~B}$ layer formation decreases when the temperature increases.

From the table 3 we note that the formation time incubation decreasing with the increasing temperature.

Based on the experimental observations of Brakman et al. ${ }^{9}$, it was shown that the incubation time $\tau$ decreases with increasing temperature.

Figure 3 shows the variation of incubation time calculated in function of the temperature for 2 hours treatment time.

To consider the effect of incubation times for the borides formation, the temperature-dependent function $\mathrm{B}(\mathrm{T})$ was incorporated in our model.

Table 2. Evolution of the absolute value of the growth rate constant according to temperature $(\tau=0)$.

\begin{tabular}{cccccccc}
\hline Température ${ }^{\circ} \mathrm{C}$ & 750 & 800 & 850 & 900 & 950 & 1000 & 1050 \\
\hline $\mathrm{k}\left(\mu \mathrm{m} . \mathrm{s}^{-1 / 2}\right)$ & 0.1481 & 0.2275 & 0.3365 & 0.480 & 0.6672 & 0.9037 & 1.1960 \\
\hline
\end{tabular}

Table 3. The values of the simulated incubation time of the Fe2B boronized layer $(\tau)$.

\begin{tabular}{rcccccccc}
\hline \multirow{2}{*}{$\mathrm{T}\left({ }^{\circ} \mathrm{C}\right) / \mathrm{t}(\mathrm{h})$} & \multicolumn{3}{c}{ experimental value of layer thickness $(\mu \mathrm{m})$} & \multicolumn{5}{c}{ Simulated incubation time $(\mathrm{s})$} \\
\cline { 2 - 8 } & 2 & 4 & 6 & 8 & 2 & 4 & 6 & Average \\
\hline $850^{\circ} \mathrm{C}$ & 20.0 & 30.0 & 38.0 & 56.0 & 217.39 & 320.19 & 389.96 & 309.18 \\
$950^{\circ} \mathrm{C}$ & 50.0 & 77.0 & 96.0 & 124 & 65.56 & 14.07 & 6.34 & 28.66 \\
$1000^{\circ} \mathrm{C}$ & 74.5 & 108 & 128 & 160 & 5.26 & 0.29 & 25.66 & 10.38 \\
\hline
\end{tabular}


The parameter B (T) given by equation (12) depends only on the temperature which has been used by several studies to estimate the thickness of the boronized layer ${ }^{24}$, this parameter does not have a physical dimension. It can be approximated by a linear equation:

$$
B(T)=\left(1-\sqrt{\frac{t}{\tau}}\right)
$$

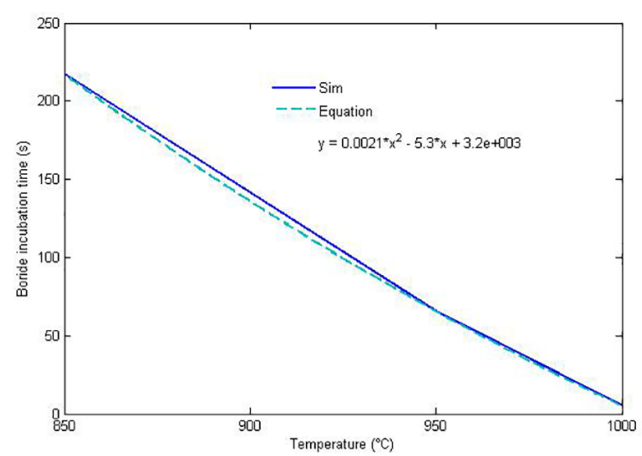

Figure 3. Incubation time according to the temperature for $2 \mathrm{~h}$.

Table 4. Simulated values of the parameter B (T) according to temperature.

\begin{tabular}{ccccc}
\hline \multirow{2}{*}{$\mathrm{T}\left({ }^{\circ} \mathrm{C}\right) / \mathrm{t}(\mathrm{h})$} & \multicolumn{4}{c}{$\mathrm{B}(\mathrm{T})$} \\
\cline { 2 - 5 } & $2 \mathrm{~h}$ & $4 \mathrm{~h}$ & $6 \mathrm{~h}$ & $8 \mathrm{~h}$ \\
\hline $850{ }^{\circ} \mathrm{C}$ & 0.792 & 0.853 & 0.880 & 0.896 \\
$950{ }^{\circ} \mathrm{C}$ & 0.936 & 0.955 & 0.963 & 0.968 \\
$1000{ }^{\circ} \mathrm{C}$ & 0.962 & 0.973 & 0.978 & 0.981 \\
\hline
\end{tabular}

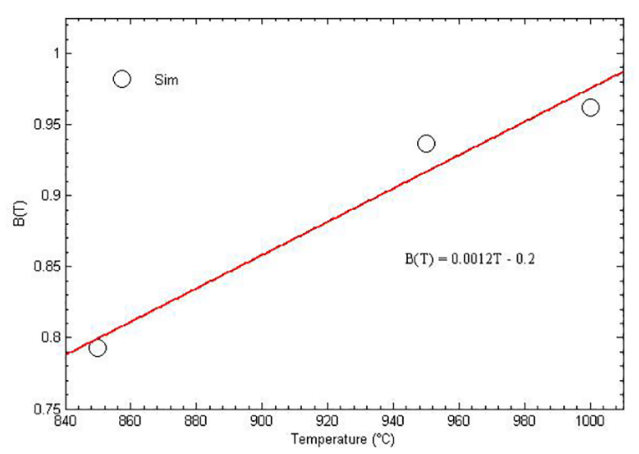

Figure 4. The B (T) Parameter as a function of temperature for 2hours treatment period.

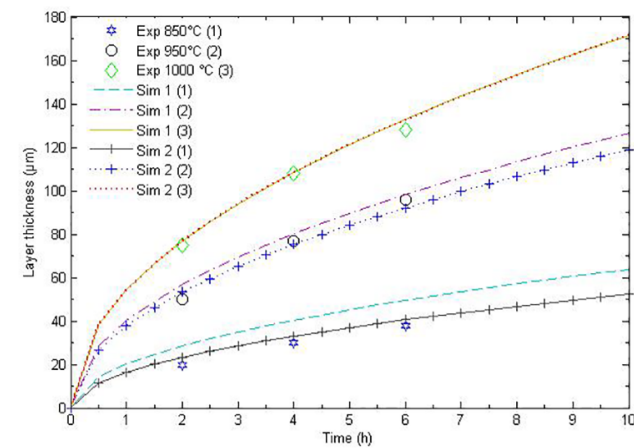

Figure 5. Comparison of the simulated thickness $(\operatorname{sim} 1),(\operatorname{sim} 2)$ measured for different temperatures.

Table 4 shows the simulated values of the parameter $\mathrm{B}(\mathrm{T})$ according to temperature, we note that $\mathrm{B}(\mathrm{T})$ increases when the temperature increase.

The variation parameter $\mathrm{B}(\mathrm{T})$ as a function of temperature for 2 hours treatment period is plotted in Figure 4, the variation of this parameter is estimated with a linear equation.

The boride incubation time for forming the $\mathrm{Fe}_{2} \mathrm{~B}$ layer on the iron substrate, was incorporated in the mathematical formulation of the simulation model in order to evaluate the growth rate constant at the $\mathrm{Fe}_{2} \mathrm{~B}$ phase.

The equation (7) giving the simulated thickness of the $\mathrm{Fe}_{2} \mathrm{~B}$ boronized layer, can be rewritten in the following way:

$$
U=k B(T) \sqrt{t}
$$

Table 5 shows the simulated values of the boronized layer thickness according to $\mathrm{B}(\mathrm{T})$; we find a good agreement between the experimental data and the calculated ones.

Figure 5 depicts the evolution of the boronized layer thickness, simulated with both methods. The first (sim 1) does not consider the incubation time of the $\mathrm{Fe}_{2} \mathrm{~B}$ layer, and it allows us to calculate the thickness with the assumption that the $\mathrm{Fe}_{2} \mathrm{~B}$ layer forms instantly at $\mathrm{t}=0$ and immediately covers the steel, the second method $(\operatorname{sim} 2)$ is calculated based on the incubation time of the $\mathrm{Fe}_{2} \mathrm{~B}$ layer.

Note that simulation $2(\operatorname{sim} 2)$ gives good results compared to (sim 1) which is justified by the importance of the incubation time.

Table 5. The thickness of the boronized layer simulated with the equation (13) and the thickness obtained by using the experimental data.

\begin{tabular}{ccccccc}
\hline & \multicolumn{5}{c}{ Layer thickness $\mathrm{Fe}_{2} \mathrm{~B}(\mu \mathrm{m})$} \\
\cline { 2 - 7 } $\mathrm{T}\left({ }^{\circ} \mathrm{C}\right) / \mathrm{t}(\mathrm{h})$ & \multicolumn{5}{c}{ simulated by using $\mathrm{B}(\mathrm{T})$ function } \\
\cline { 2 - 7 } & $2 \mathrm{~h}$ & $4 \mathrm{~h}$ & $6 \mathrm{~h}$ & $2 \mathrm{~h}$ & $4 \mathrm{~h}$ & $6 \mathrm{~h}$ \\
\hline $850^{\circ} \mathrm{C}$ & 20 & 30 & 38 & 23.41 & 33.11 & 40.55 \\
$950^{\circ} \mathrm{C}$ & 50 & 77 & 96 & 53.22 & 75.26 & 92.17 \\
$1000^{\circ} \mathrm{C}$ & 74.5 & 108 & 128 & 76.68 & 108.4 & 132.8 \\
\hline
\end{tabular}


Comparing the results, given by the numerical simulation with experimental data, the medium error generated from model was $2.8 \mu \mathrm{m}$.

From Figure 5 we note that the result of simulation $(\operatorname{sim} 2)$ considers the effect of the boride incubation time $(\tau)$ during the formation of $\mathrm{Fe}_{2} \mathrm{~B}$ layer were in good agreement with the experimental data.

For the temperature $1000^{\circ} \mathrm{C}$ we note that the simulation ( $\operatorname{sim} 1)$ coincides with the results of the simulation $(\operatorname{sim} 2)$, this is interpreted as the incubation time decreases when the temperature increases which the incubation time is negligible for a temperature more than $1000^{\circ} \mathrm{C}$.

\section{Conclusion}

In this work, we developed a mathematical model based on the second law of Fick to simulate the incubation time of the $\mathrm{Fe}_{2} \mathrm{~B}$ boronized layer formation obtained by boronizing the XC38 steel. From a kinetic point of view, the thicknesses of borided layers follow a parabolic law. Basing on experimental results, the boron activation energy was estimated as 207.8 $\mathrm{kJ} / \mathrm{mol}$ for XC38 steel.

Using this numerical simulation, we can estimate the incubation time and calculate the thickness of boronized layer considering the incubation time.

We see through this work that the incubation time for the formation of the boronized layer is very important to calculate the thickness of the $\mathrm{Fe}_{2} \mathrm{~B}$ boronized layer, and the incubation time decreases when the temperature increases, and it is negligible for temperatures more than $1000^{\circ} \mathrm{C}$. The results obtained in this work clearly show the influence of these parameters.

The Comparison between the simulation result and the experimental data allows us to confirm the validity of our model.

The accuracy of the simulation results depends highly on a series of measurements obtained experimentally. To simulate the thickness values of boride layers with good exactness, it is necessary to increase the number of measurements.

\section{References}

1. Matuschka AG. Boronizing. Munich: Carl Hanser Verlag; 1980.

2. Sinha AK. Boriding (Boronizing) of Steels. In: ASM Handbook Volume 4 - Heat Treating. Materials Park: ASM International; 1990. p. 437-447.

3. Allaoui O, Bouaouadja N, Saindernan G. Characterization of boronized layers on a XC38 steel. Surface and Coatings Technology. 2006;201(6):3475-3482.

4. Yu LG, Chen XJ, Khor KA, Sundararajan G. FeB/Fe2B phase transformation during SPS pack-boronizing: Boride layer growth kinetics. Acta Materialia. 2005;53(8):2361-2368.

5. Keddam M, Chentouf SM. A diffusion model for describing the bilayer growth $(\mathrm{FeB} / \mathrm{Fe} 2 \mathrm{~B})$ during the iron powder-pack boronizing. Applied Surface Science. 2005;252(2):393-399.
6. Pertek A. Gas Boriding Conditions for the Iron Borides Layers Formation. Materials Science Forum. 1994;163-165:323-328.

7. Popeau P. Diagramme d'équilibre alliages binaires. Techniques de l'Ingénieur. 1986;M70(1):129.

8. Massalski TB, Okamoto H, Subramanian PR, Kacprzak L, eds. Binary Alloy Phase Diagrams. 2nd ed. Materials Park: ASM International; 1990.

9. Brakman CM, Gommers AWJ, Mittemeijer EJ. Boronizing of $\mathrm{Fe}$ and $\mathrm{Fe}-\mathrm{C}, \mathrm{Fe}-\mathrm{Cr}$, and $\mathrm{Fe}-\mathrm{Ni}$ alloys: Boride-layer growth kinetics. Journal of Materials Research. 1989;4(6):1354-1370.

10. Kunst H, Schaaber O. The surface boriding of steel. Pt. 2. Growth mechanism and structure of intermediate and diffusion layers. Härterei-Technische Mitteilung. 1967;22(4):275.

11. Ucar N, Aytar OB, Calik A. Temperature behaviour of the boride layer of a low-carbon microalloyed steel. Materiali in Tehnologije. 2012;46(6):621-625.

12. Keddam M. A kinetic model for the borided layers by the paste-boriding process. Applied Surface Science. 2004;236(14):451-455.

13. Campos-Silva I, Ortiz-Domínguez M, Bravo-Bárcenas O, Doñu-Ruiz MA, Bravo-Bárcenas D, Tapia-Quintero C, et al. Formation and kinetics of $\mathrm{FeB} / \mathrm{Fe} 2 \mathrm{~B}$ layers and diffusion zone at the surface of AISI 316 borided steels. Surface and Coatings Technology. 2010;205(2):403-412.

14. Campos I, Oseguera J, Figueroa U, Garcia JA, Bautista O, Keleminis G. Kinetic study of boron diffusion in the pasteboroding process. Materials Science and Engineering: $A$. 2003;352(1-2):261-265.

15. Bouaziz SA, Boudaoud N, Zanoun A. Boruration thermochimique d\&apos;un acier C38 dans un bain de sels borax-SiC. Matériaux et Techniques. 2009;97(4):253-259.

16. Mebarek B, Bouaziz SA, Zanoun A. Simulation model to study the thermochemical boriding of stainless steel "AISI 316" (X5CrNiMo17-12-2). Matériaux et Techniques. 2012;100(2):167175.

17. Yang H, Wu X, Yang Z, Pu S, Wang H. Enhanced boronizing kinetics of alloy steel assisted by surface mechanical attrition treatment. Journal of Alloys and Compounds. 2014;590:388395.

18. Genel K, Ozbek I, Bindal C. Kinetics of boriding of AISI W1 steel. Materials Science and Engineering: A. 2003;347(12):311-314.

19. Abdellah ZN, Keddam M, Chegroune R, Azouani O, Allaoui O, Elias A. Characterization and boriding kinetics of C38 carbon steel: effect of the process time. Materiaux et Technique. 2012;100(3):271-278.

20. Hallemans B, Wollants P, Roos JR. Thermodynamic assessment of the Fe-Nd-B phase diagram. Journal of Phase Equilibria. 1995;16(2):137-149.

21. Casadesus P, Frantz C. La boruration du fer et des aciers par bombardement ionique avec le diborane. Les Mémoires scientifiques de la Revue de Métallurgie. 1978;81-91.

22. Keddam M. Simulation of the growth kinetics of the (FeB/ Fe2B) bilayer obtained on a borided stainless steel. Applied Surface Science. 2011;257(6):2004-2010. 
23. Keddam M, Bouarour B, Nait Abdellah Z, Chegroune R. The effective diffusion coefficient of boron in the Fe2B layers formed on the iron substrate. MATEC Web of Conference. 2013;3:01012.

24. Campos-Silva I, Ortiz-Domínguez M, Bravo-Bárcenas O, Doñu-Ruiz MA, Bravo-Bárcenas D, Tapia-Quintero C, et al. Formation and kinetics of $\mathrm{FeB} / \mathrm{Fe} 2 \mathrm{~B}$ layers and diffusion zone at the surface of AISI 316 borided steels. Surface and Coatings Technology. 2010;205(2):403-412.
25. Sen S, Sen U, Bindal C. The growth kinetics of borides formed on boronized AISI 4140 steel. Vacuum. 2005;77(2):195-202.

26. Mebarek B, Madouri D, Zanoun A, Belaidi A. Simulation model of monolayer growth kinetics of $\mathrm{Fe} 2 \mathrm{~B}$ phase. Matériaux \& Techniques. 2015;103(7):703-710.

27. Campos I, Torres R, Bautista O, Ramírez G, Zúñiga L. Effect of boron paste thickness on the growth kinetics of polyphase boride coatings during the boriding process. Applied Surface Science. 2006;252(6):2396-2403. 